\title{
INELASTIC DYNAMIC ANALYSIS OF STEEL STRUCTURES
}

\author{
J. Lord*, J.B. Hoerner**, M. Zayed***
}

\section{SUMMARY}

\begin{abstract}
This paper updates a previously described analytical approach $(1,2)$ using computer technology to investigate the time-dependent material non-linear behaviour of two dimensional moment-frame, trussframe, and braced-frame steel structures during significant excursions into the post-elastic range. The approach includes considerations for energy analysis; element buckling; stable or unstable mechanism formation; yield capacity reduction resulting from interaction of axial load and bending moment; stiffness degradation; $\mathrm{P}-\delta$ effects; viscous damping; joint panel zone deformation; and also incorporates a suitable element loaddeformation relationship. The computer program NLDYN2 which incorporates this approach has been implemented successfully on many steel structures ranging from 60-story moment frames to braced frames having aspect ratios of up to 10 .
\end{abstract}

\section{INTRODUCTION}

The survival of many types of structures during periods strong ground shaking very often depends on their post-elastic behaviour. Experience has taught us that structures having a large capacity to absorb and dissipate energy while controlling distortion are those most likely to survive. If distortion is sufficiently well-controlled, then damage may also be controlled. This is evidenced at least in the United States by the growing trend of establishing seismic performance criteria based upon controlling the damage potential to within pre-determined acceptable limits rather than customary specific strength and stiffness considerations. If survival or damage control during seismic or other vibratory disturbances is important and is expected to depend on the dynamic behaviour of a structure in the post-elastic range, it is evident that not only should the behaviour of the structural system, its components and their connections be predictable during such excursions, but also the material itself should be predictable. The analytical approach outlined in this paper assumes predictability of the structure as a whole when undergoing significant excursions into the post-elastic range. As such, the application of the approach must be limited to materials and structural configurations in which predictability is reasonably assured. To-date applications of NLDYN2 have been confined to two-dimensional analyses of moment frame, truss frame, $x$ and $\mathrm{K}$ braced frame structures or combinations thereof in structural steel construction. The paper focuses primarily on some of the

* President, Seismic Engineering Associates, Ltd. , Formerly General Manager, Group 10 Systems Division, Albert $C$. Martin and Associates, Los Angeles, California.

* Senior Systems Engineer, Group 10 Systems Division, Albert C. Martin and Associates, Los Angeles, California.

*** Senior Systems Engineer, Group 10 Systems Division, Albert C. Martin and Associates, Los Angeles, California. significant theoretical aspects of the material non-linear dynamic behaviour of steel structures as incorporated in a computer program NLDYN2. As such, it expands and updates the two previously published papers $(1,2)$ which review the theory and program implementation of the computer program NLDYN, an earlier version of NLDYN2.

\section{THEORY}

Prior to the advent of third-generation, high-speed digital computers, structural analyses were usually made using a linear elastic assumption. Investigations of the material non-linear behaviour of structures were confined or reduced to simple singledegree-of-freedom systems. Extrapolations of such investigations to predict the behaviour of larger, more complex structures were largely based upon engineering judgment. Similarly, physical testing programs generally were devised to evaluate material properties, ultimate strength capacities and buckling mechanisms of individual elements rather than assemblages intended to represent full-scale structural components and their connections. Further, loading sequences were frequently monotonic in nature.

Today, many analytical programs have been devised to investigate the material non-linear behaviour of structural steel systems during dynamic loading conditions. Facilities and programs for physical testing have greatly improved and have provided the basis for selecting one or another analytical assumption. A review of some of the important theoretical considerations follows:

\section{FORCE-DEFLECTION RELATIONSHIP}

Depending upon the particular geometric configuration of a structure, component beam-column and truss elements and their connections may experience primary and secondary force and distortion demands induced during periods of strong ground shaking, by virtue of their axial, flexural, 
shear and torsional stiffnesses. Little physical testing has been done to date on assemblages which consider all four types of load. For this reason, the NLDYN2 formulation does not include torsional loads. And thus, is limited to analyses of twodimensional structures or three-dimensional structures in which torsional loads are not important.

In considering the interaction of axial, flexural and shear loads, NLDYN2 first attempts to satisfy primary axial load demand induced in any element. In doing so, buckling criteria are evaluated using the AISC Specification (3), Figure 1.

For slender elements the forcedeflection curve depicted in Figure 2 is considered appropriate. Reference to Figure 2 indicates a bilinear approximation is assumed. The slope of the $P-\Delta$ load cycle in the elastic range is based upon the elastic and shear moduli of the element. In the range beyond yield, the change in slope of the $\mathrm{P}-\Delta$ load cycle represents strain hardening in tension or compression and may be specified at any value. The default value is set at 5\%, based upon a consensus of test data for most structural steels. In compression, the axial load capacity is seen to be governed by elastic buckling, except for load cycles which induce sufficiently large axial deformations to reduce the axial compressive yield capacity, $P_{y C}$, by strain hardening effects to a value less than the elastic buckling capacity $\mathrm{P}_{\mathrm{Cr}}$. Once an element has buckled, elastically, the element is assumed to continue to carry its buckling load or fraction thereof until it returns to its displacement configuration at the inception of buckling at which time it regains its linear elastic stiffness properties.

Element buckling of this nature is illustrated in Figure 2, in following load steps 1 through 4, 6 through 9, and 11 through 15. NLDYN2 can accommodate an option to be specified which allows a degradation of load-carrying capacity of an elastically buckled element with increasing axial deformation. For illustrative purposes, the curve in Figure 4 has been suggested (4) as being an applicable stiffness degradation curve for slender tubular steel elements. It is based upon recent tests (5) carried out in conjunction with the design of an offshore drilling platform. The mechanism used to detect the instant of time at which a previously buckled element resumes its original elastic stiffness properties is based upon the element's accumulated buckling during deformation.

For stocky elements, the force deflection curve illustrated by Figure 3 is considered an appropriate curve for use in most analyses of steel-framed structures. Again, a bilinear $\mathrm{P}-\Delta$ relationship is assumed with provision made to account for strain hardening. The load cycle is considered stable throughout the analysis. In general, the axial load-carrying capacity is governed by yielding in either tension or compression. Only in cases where large axial deformations are experienced will the effect of strain hardening possibly increase the compression load capacity, Pyc, to a level in excess of the elastic buckling load, as indicated in Figure 3 in load steps 4 through 7. In the event elastic buckling should occur, the post-buckling degradation of load-carrying capacity of elastically buckled elements is as described previously. Inelastically buckled elements are assumed to continue to carry the elastic yield load modified by the specified strain hardening effect. In determining the effective length of $a$ compression element, end-restraint is an important factor. The AISC specification formulation is embodied in NLDYN2 for computing effective length factors.

\section{MOMENT-CURVATURE RELATIONSHIP}

A simple bilinear moment-curvature formulation characterized by an elastic stiffness $k$, yield moment $M_{Y}$, and strain hardening rate $\mathrm{p}$, Figure 5 , has been incorporated in NLDYN2. The results of many test programs suggest this formulation is adequate for steel-framed structures, especially in cases where distortions are reasonably well-controlled.

The presence of axial load is known to have a significant effect on the yielding mechanism of any element. Figures 6 and 7 are included to illustrate the axial load/ moment interaction formulation incorporated in NLDYN2. As noted previously in this paper, for elements subjected to axial tension or compression, NLDYN2 gives first consideration to satisfying the axial load demand. Thus, entering the interaction curves, Figures 6 and 7, with the full axial load demand value establishes a reduced yield moment value for the element. It is this reduced $M_{y}$ value that is used to detect a plastic hinge formation at a particular time step.

\section{Owing to change in axial deformation} with time, the actual $M-\phi$ diagram may follow the dashed line curve shown in Figure 5 instead of a bilinear curve. A procedure to account for this stiffness degradation is as follows;

At the beginning of each time step a rotational stiffness $\mathrm{pk}$ is assumed. This incremental element stiffness is used to calculate the lateral stiffness of the structure. Solving the equations of motion, $\phi_{t+\Delta t}$ is computed, from which, $M_{t+\Delta t}^{\prime}$ (actual) and $M_{t+\delta t}^{\prime}$ (projected) are determined. The difference $\Delta \mathrm{M}_{t}$ is then added to the load acting on the structure in the next time step. After determining $M_{t+\Delta t}$ (actual) residual forces acting on the joint from equilibrium consideration can be determined and their effect are added to the next time step. Thus, an equilibrium check is achieved.

\section{Ductility}

The notion of using ductility as a measure of the amount of inelastic action in a joint or element is widespread. Ductility is usually expressed in terms of the ductility factor $\eta$ defined as;

$$
\eta=\phi / \phi_{Y}
$$

where $\phi$ is the total rotation and $\phi_{y}$ is the rotation at which plastic hinge is formed. 
For elements subjected to large axial loads, it is evident that the reduction in yield moment may be significant. This can lead to high element ductility ratios, $\eta$, even though hinge rotations are in fact very small and may in fact be considerably less than the rotation at yield in the absence of axial load. Thus, the use of element ductility factors is a measure of joint distortion can be misleading if the effect of axial load is significant. A more direct measure is, of course, the actual rotations $\phi$. NLDYN2 monitors these rotations in addition to the ductility factor $\eta$.

\section{p-Delta Effect}

The sidesway movements of a structure when subjected to gravity loading induces an effect generally referred to as the P- $\Delta$ effect. The effect increases the overturning moment on the structure and tends to increase sidesway and the lateral periods of vibration. NLDYN2 incorporates this effect by expressing the consistent geometric stiffness matrix for each element in the form;

$$
\left\{\begin{array}{c}
v_{i} \\
M_{i} \\
v_{j} \\
M_{j}
\end{array}\right\}=\frac{P}{30}\left[\begin{array}{cccc}
36 / L & 3 & -36 / L & 3 \\
& 4 L & -3 & -L \\
& & 36 / L & -3 \\
\text { symm. } & & & 4 L
\end{array}\right]\left\{\begin{array}{c}
r_{i} \\
\phi_{i} \\
r_{j} \\
\phi j
\end{array}\right\}
$$

where $P$ is the axial load and $L$ the element length. Many formulations have been developed to represent the effect analytically. The above approach appears adequate and sufficient except in cases developing excessive sidesway.

\section{NUMERICAL INTEGRATION TECHNIQUES}

The equations of motion for the inelastic structural system are solved by a properly devised numerical integration scheme. No such scheme is perfect; however, the merits of accuracy, stability, and economy guide a proper selection. Consideration was originally given to the socalled Newmark $\beta$-method as well as the Runge-Kutta method. More recently a differential scheme, developed by wilson and his co-workers, was implemented in the program. However, this has since been replaced by the iterative Newmark $\beta$-method. The ability of this latter scheme to handle equations of motion with varying stiffness and the short time involved in effecting iterative convergence favoured this change.

The Newmark $\beta$-method uses known responses at a given time to compute responses at a time incrementally later. Initially it is assumed that the acceleration is unchanged so that

$$
\ddot{r}_{t+\Delta t}=\ddot{r}_{t} \text {. }
$$

Velocities and accelerations at the later time are then computed from the equations

$$
\dot{r}_{t+\Delta t}=\dot{r}_{t}+\frac{1}{2}\left(\ddot{r}_{t}+\ddot{r}_{t+\Delta t}\right) \Delta t
$$

and

$$
r_{t+\Delta t}=r_{t}+\dot{r}_{t} \Delta t+\left(\left(\frac{1}{2}-\beta\right) \ddot{r}_{t}+\beta \ddot{r}_{t+\Delta t}\right) \Delta t^{2} .
$$

The resulting values are substituted into the equations of motion for calculation of an altered acceleration at the new time. Thus;

$$
\begin{aligned}
\ddot{r}_{t+\Delta t}= & \left.-\ddot{r}_{g}-[M]-1[C] \dot{r}_{t+\Delta t}-[M]\right]^{-1} \\
& {[\mathrm{~K}] r_{t+\Delta t} . }
\end{aligned}
$$

Comparison of the primed and unprimed acceleration values reveals convergence, the difference being acceptably minute, or that iteration, with the unprimed accelerations replaced by the primed values in equation (2), is to be undertaken. Successive iteration eventually yields satisfactory convergence and the equations of motion are thereby solved at this new time.

The adoption of this approach was necessitated by the need to analyze the stability of certain types of structures with zero or negative stiffness.

A very slight improvement in computer solution time and numerical accuracy can be expected by using the Newmark $\beta$-method versus the Wilson scheme.

\section{OTHER CONSIDERATIONS}

Other considerations such as damping, energy analysis, panel distortions, effect of non-structural elements, program implementatjon, etc. are as previously
described

\section{CONCLUDING REMARKS}

The computer program NLDYN2 now embodies a more flexible numerical integration routine capable of analyzing the stability of a wide range of steel-framed structures during periods of mechanistic behaviour. In addition, the ability of NLDYN2 to investigate the post-elastic behaviour of many types of steel-framed structures when subjected to strong ground shaking or other vibratory loads has been demonstrated.

Recent program developments permit careful time-dependent buckling analyses of both slender and stocky elements to be made and the effect of such buckling on the overall structure to be assessed.

\section{ACKNOWLEDGMENTS}

The valuable comments of Joseph Kallaby, Earl \& Wright, Consulting Engineers, San Francisco, California is acknowledged.

The technical support of the Group 10 Systems Division of Albert C. Martin and Associates, Los Angeles, California is greatly appreciated.

\section{REFERENCES}

1. Lord, J., Meyer, C., Hoerner, J. B., Zayed, M. M., "Inelastic Dynamic Analysis of a 60 story Building". Proc. 5th World Conference Earthquake Engineering, Volume II, paper 165, Rome, 
Italy, 1973.

2. Meyer, C., "Inelastic Dynamic Analysis of Tall Buildings", Earthquake Engineering and Structural Dynamics, Vol. 2, pp. 325-342 (1974).

3. American Institute of steel Construction, Manual of Steel Construction, 7 th Edition, New York (1970).

4. Kallaby, J., Millman, D. N., "Inelastic Analysis of Fixed Offshore Platforms for Earthquake Loading", OTC Paper 2357,7 th Annual Offshore Technology Conference, Houston, Texas, May 3-5. 1975.

5. Bouwkamp, J. G., "Buckling \& PostBuckling Strength of Circular Tubular Sections", OTC paper 2204, 7 th Annual Offshore Technology Conference, Houston, Texas, May 3-5, 1975.

\section{NOTATION}

B Newmark Beta factor

[C] structure damping matrix

[K] structure stiffness matrix

I frame element span

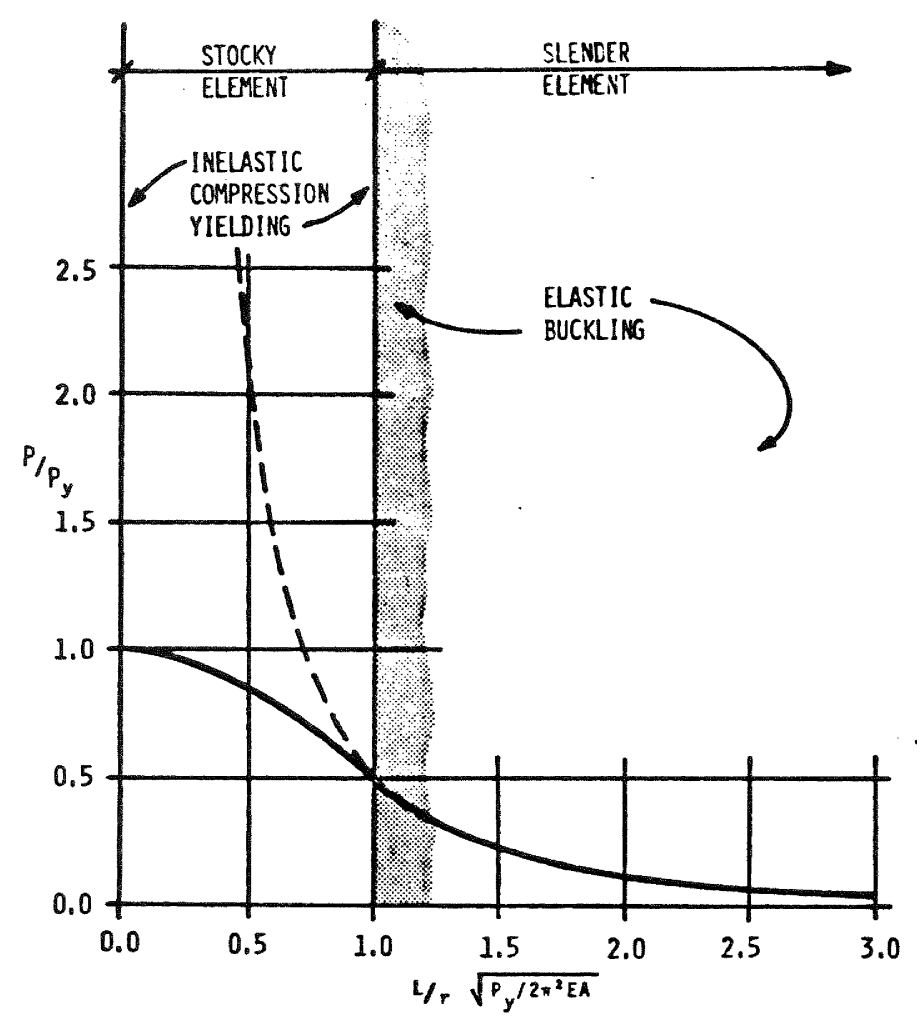

FIGURE 1: BUCKLING LOAD CURVE
$M_{i}$ bending moment at node $i$

My yield moment

[M] structure mass matrix

$p$ rate of strain hardening

$p$ axial load in frame element

$\left\{r_{t}\right\}\left\{\dot{r}_{t}\right\}\left\{\ddot{r}_{t}\right\}$ displacement, velocity, and acceleration vector a time $t$

$\left\{\ddot{x}_{g}\right\}$ ground acceleration vector

$V_{i}$ shear force a node i

$\Delta$ axial deformation of a frame element

$\eta$ ductility factor $\phi / \phi_{y}$

$\phi$ total end rotation of a frame element

y $\phi$ yield rotation

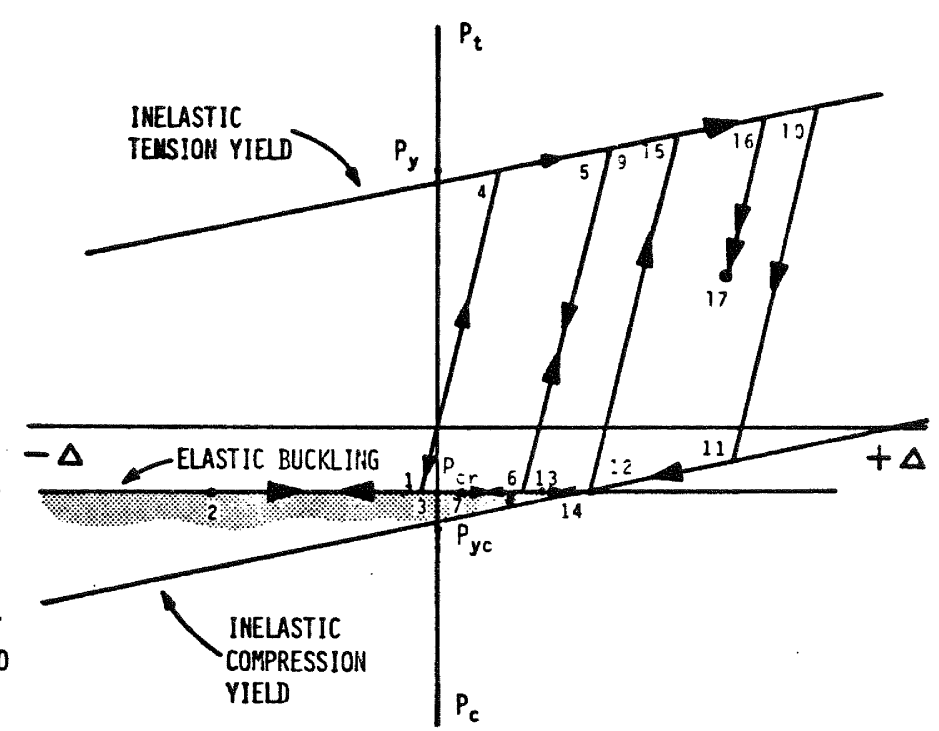

FIGURE 2: P- $\triangle$ LOAD CYCLE FOR SLENDER ELEMENT 


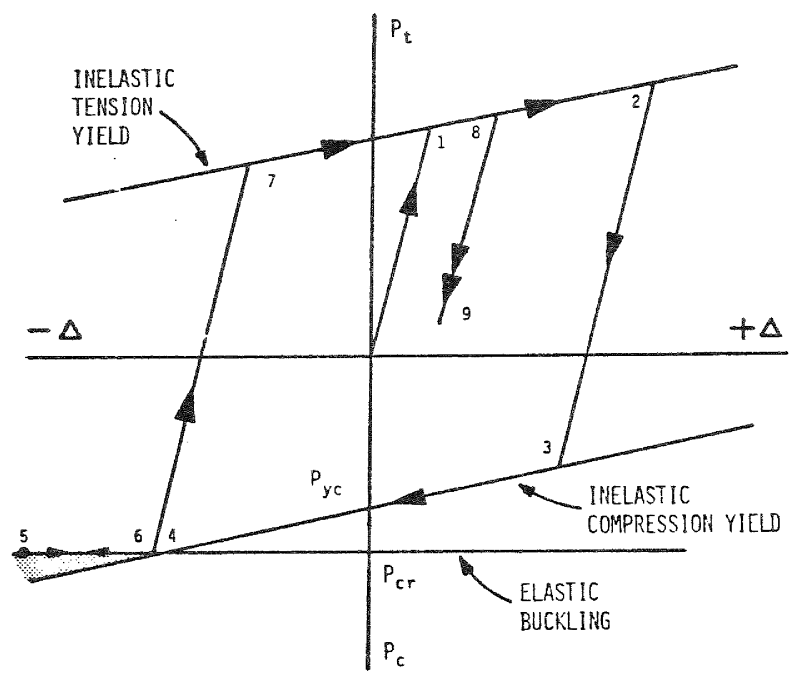

FIGURE 3: P- $\triangle$ LOAD CYCLE FOR STOCKY ELEMENT

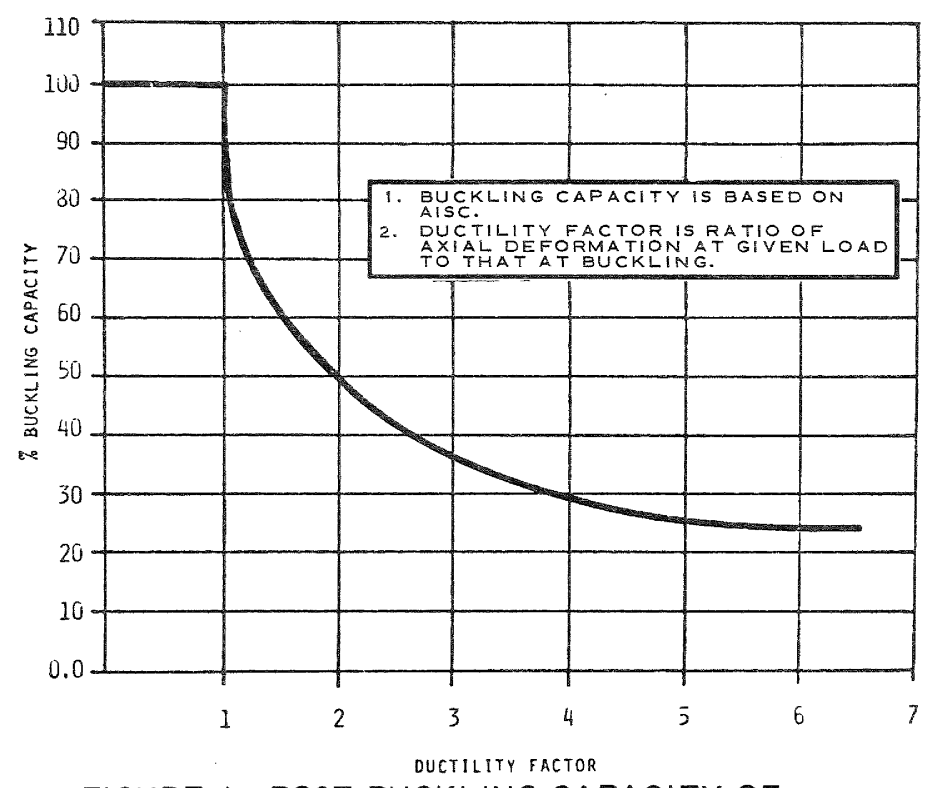

FIGURE 4: POST BUCKLING CAPACITY OF SLENDER COMPRESSION ELEMENTS

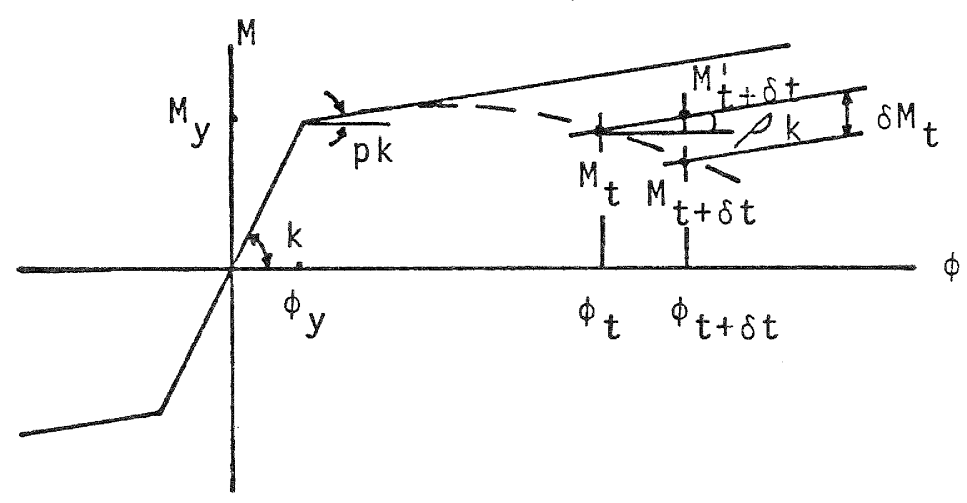

FIGURE 5: BILINEAR FORMULATION

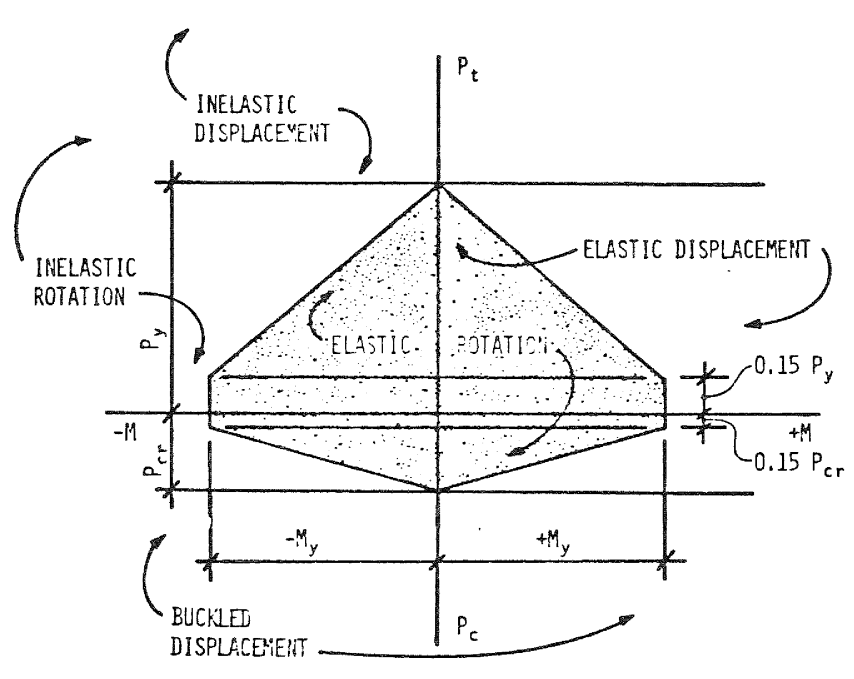

FIGURE 6: AXIAL LOAD/MOMENT INTERACTION FOR SLENDER ELEMENT PRIOR TO ANY STRAIN HARDENING

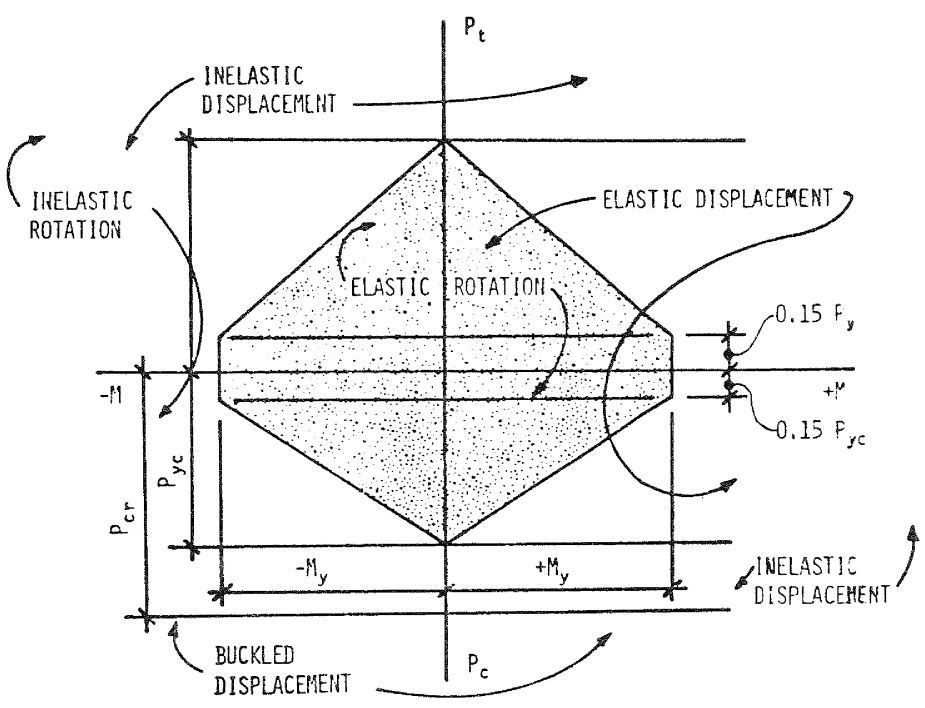

FIGURE 7: AXIAL LOAD-MOMENT INTERACTION FOR STOCKY ELEMENT PRIOR TO ANY STRAIN HARDENING 